\title{
Article \\ Challenges in the Integration of Quality and Innovation Management Systems
}

\author{
Ana Lopes ${ }^{1}$, Daniel Polónia ${ }^{1,2}\left(\mathbb{D}\right.$, Adriana Gradim ${ }^{1}$ and Jorge Cunha ${ }^{3, *(\mathbb{C}}$ \\ 1 Department of Economics, Management, Industrial Engineering and Tourism (DEGEIT), University of Aveiro, \\ 3810-193 Aveiro, Portugal; ajml@ua.pt (A.L.); dpolonia@ua.pt (D.P.); adrianacoutinho@ua.pt (A.G.) \\ 2 Research Unit on Governance, Competitiveness and Public Policies (GOVCOPP), University of Aveiro, \\ 3810-193 Aveiro, Portugal \\ 3 ALGORITMI Research Center, School of Engineering, University of Minho, 4800-058 Guimarães, Portugal \\ * Correspondence: jscunha@dps.uminho.pt
}

check for updates

Citation: Lopes, A.; Polónia, D.; Gradim, A.; Cunha, J. Challenges in the Integration of Quality and Innovation Management Systems. Standards 2022, 2, 52-65. https: / / doi.org/10.3390/standards2010005

Academic Editor: Dimitrios

E. Koulouriotis

Received: 11 October 2021

Accepted: 22 December 2021

Published: 17 February 2022

Publisher's Note: MDPI stays neutral with regard to jurisdictional claims in published maps and institutional affiliations.

Copyright: (c) 2022 by the authors. Licensee MDPI, Basel, Switzerland. This article is an open access article distributed under the terms and conditions of the Creative Commons Attribution (CC BY) license (https:// creativecommons.org/licenses/by/ $4.0 /)$.

\begin{abstract}
Seeking to reduce the number of inconsistencies in their processes, many organisations choose to implement the ISO 9001:2015 quality management standard. Their aim is to improve operational performance while, at the same time, they cope with increased pressures from the market to present innovative products and solutions and from the stakeholders to implement new organizational methods. This work intends to investigate how organisations can leverage ISO 9001:2015 in implementing the ISO 56002:2019 innovation management standard, given that both standards have a high degree of compatibility with each other. For that purpose, meetings were held with senior managers and quality managers of three Portuguese SMEs to discuss the existing potential challenges and gaps in the integration of both management systems. The results point to the existence of a significant set of practices in the field of quality that can support and facilitate the formalization of integrated management systems. Nevertheless, generalization of the results should be avoided, and more research is needed, since the integration of management systems is often conditioned by cost and time related issues. Furthermore, it is disputable whether a company can simultaneously reach a high level of efficiency (brought about by implementing a quality management system) and a high level of innovation (made possible by the implementation of an innovation management system) thus jeopardizing the implementation of an integrated management system.
\end{abstract}

Keywords: innovation; quality; management system; integration; standardization; ISO 56002:2019; ISO 9001:2015

\section{Introduction}

Seeking to reduce as much as possible the number of inconsistencies, waste or nonconformities in their processes, many organisations choose to implement the ISO 9001:2015 quality management standard, aiming to improve their entire operational performance by implementing and promoting the specifications that the standard conveys about continuous improvement and risk-based thinking and adopting a process approach.

In addition, ISO 9001:2015 also conveys a set of seven quality principles that, when instilled and applied in the day-to-day of organisations, increase the likelihood that they will demonstrate to their customers a higher level of excellence and demonstrate the organisations' ability to provide products and services that consistently meet customer requirements through the implementation of the content referred to in their requirements [1].

However, even though they have implemented ISO 9001:2015, what companies sooner or later end up seeing is growing instability in the domains of innovation in their industry, which ends up creating an impasse and a need to be constantly alert and able to respond to the different threats that are being posed to them.

One of the ways organisations can see as a plausible option to maintain and survive in the competitive market where they operate is through the adoption/integration of 
innovation standards [2]. Currently, many countries have their own innovation standard, which includes recommendations and innovation techniques intended to facilitate the entire process of managing innovation or inherent innovative activities. However, when compared to each other, they show that they focus on different aspects or focus on different themes, with only a few have similarities.

While preparing the most recent version of ISO 9001:2015, two new themes were suggested to complement the existing standard. Risk and innovation were addressed, and it was concluded that innovation management would require the inclusion of a wide range of contents and require all organisations to comply with the innovation requirements if they wanted to have their quality management systems certified. It was then decided that the new version would only include a greater focus on risk management and that the subject of innovation management would be further developed elsewhere [3].

By 2014, the International Organization for Standardization (ISO) set up the ISO/Technical Commission 279, aiming to provide tools, approaches and methods using the holistic approach to managing innovation, its implementation and its interactions with stakeholders in the innovation chain.

Its main objective was to standardise tools and methods dedicated to the field of innovation and in interactions between all actors in innovation management for industrial, environmental and social benefits. The strategies followed pursued the "integration of sustainable development issues in the context of innovation" and the "coherence of an innovative approach with other existing international standards".

From work developed by the ISO/TC 279, a set of five documents was already published:

1. ISO 56000:2020-Innovation management-Fundamentals and vocabulary [4].

2. ISO 56002:2019-Innovation management-Innovation management systemGuidance that guides the establishment, implementation, maintenance and continual improvement of an innovation management system used in all established organisations [5].

3. ISO 56003:2019-Innovation management-Tools and methods for innovation partnershipGuidance provides a guide for innovation partnerships based on an innovation partnership framework and the sample corresponding tools [6].

4. ISO/TR 56004:2019-Innovation Management Assessment-Guidance that helps the user to understand why it is beneficial to carry out an Innovation Management Assessment (IMA), what to assess and how to carry out the IMA [7].

5. ISO 56005:2020-Innovation management-Tools and methods for intellectual property management-Guidance that proposes guidelines for supporting the role of IP within innovation management [8].

The work developed by ISO/TC 279 has as an essential requirement the development of standards according to the ISO Annex SL (a section of the ISO/IEC Directives part 1 that prescribes how ISO Management System Standard (MSS) standards should be made compatible).

ISO 56002:2019 is a guidelines standard following a Type B Management System Standard (MSS) [9,10], whereas ISO 9001:2015 [11] is a requirements standard following a Type A MSS, making incompatible the auditing of an integrated management system that implements these two standards. However, in the scope of the ISO Technical Commission 279, under development (stage 20.00-Preparation-New project registered in TC/SC work programme) is the ISO/AWI 56001 (Innovation management-Innovation management system-Requirements) [12] that will be articulated with the requirements of the ISO 56002:2019 and will follow a Type A MSS. For that purpose, and as starting point for analysis and discussion, in this work, it was considered the ISO 56002:2019, noting the subtlety that it is not a requirements standard but a guidelines standard.

As such, this work intends to investigate to what extent an organisation can leverage ISO 9001:2015 (that it has already implemented) to satisfy ISO 56002:2019 guidelines, given that both standards have a high degree of compatibility, as they follow the structure present in Annex SL. As emphasized by [13], as long as it is possible to identify the 
similarities between both the innovation management system and the quality management system, it is possible to incorporate innovation management in any type of integrated management system.

Information was gathered from different studies and scientific investigations on the entire scope of the subject under study to analyse the evolution of innovation standards in several countries. Based on this analysis, the potential for integration between quality and innovation management systems was studied, namely in terms of benefits and difficulties associated with this type of integration. Then, a questionnaire was applied to a panel of three industrial companies to identify difficulties and expected benefits with the integrated adoption of ISO 56002:2019 and ISO 9001:2015.

With the results of this evaluation, it was possible to carry out a sustained comparison on the context of innovation of the companies and verify which factors influence negatively and positively the process of adopting this innovation standard. The approach adopted in this study follows the suggestion of [13]: a company should start the integration of an innovation management system by adapting a management system already implemented in the organisation (which is usually the quality management system) and then add additional processes, practices and procedures according to the requirements of the standards underlying the innovation management system.

However, it should be recognized that the integration of both systems is not easy [14]. On the one hand, it is necessary to balance the "free nature" of innovation with the constraints imposed by a management system [13]. In fact, the innovation management field is less well-defined and intrinsically more diverse and uncertain $[15,16]$. On the other hand, the quality management system is mainly focused on the conformance to standards, while innovation is about breaking new ground [17] such as, for example, the introduction of artificial intelligence into new products [18]. Therefore, companies face a big challenge when trying to integrate both quality management and innovation management systems in a coherent, meaningful and practical way [14].

The work concludes with a synthesis and critical reflection for implementing new solutions for the organisations' innovation processes.

This paper contributes to filling a gap in the literature identified by [2]: the lack of research about how to implement and integrate an innovation management system with other management systems already existent in a company. Since most companies have already implemented at least one management system (e.g., quality management system, environmental management system, occupational health and safety management system), it is important to assess the challenges and clearly design the method of implementation and integration of the innovation management system to avoid conflicts and problems between the management systems and to make the process of integration as successful as possible.

\section{From Quality to Innovation}

\subsection{Historical Background on Quality}

Today, it is common to come across several situations where the term "quality" is used. However, it can be associated with different areas, from the price and services provided to the aesthetic appearance, the cost of the product's life cycle, respect for the environment or functional aspects of a product or service.

In the past, although the term was commonly used and relatively easy to recognise, there was a specific difficulty in finding a definition, the main reason being the fact that there were different perceptions and interpretations that everyone had about it.

In 1987, due to the proven lack of uniformity and congruence in the establishment and definition of terms and matters relating to quality management systems, ISO began to create a series of quality standards to improve and promote the growth of organisations [1].

The first standard in the series began as ISO 9001:1987 [19], which focused on the concept of Quality Assurance. It then evolved to ISO 9001:1994 [20], where the updates were based around the concept of preventive actions. Later, ISO 9001:2000 [21] was elab- 
orated, where the concept of Quality Management to improve organisational processes was approached, and eight years later, a new version of the standard would appear, which would only have a reduced number of changes compared to its previous version [22].

This series of standards would come to have as its primary purpose to seek to transmit and describe the base contents, namely fundamental concepts, principles and vocabularies used in the description of contents of other standards of the 9000 standards series (e.g., ISO 9000:2015 [23], ISO 9001:2015 [11], ISO 9004:2018 [24] and ISO 19011:2018 [25]).

\subsection{Innovation and the ISO 9001:2015 Revision}

As previously mentioned, ISO 9001:2008 promoted continuous improvement and orientation towards organisations that seek to add value to their business model through the implementation and operationalisation of a Quality Management System.

As for the 2015 version, at the beginning of its creation, the intention was to insert two new components, one related to innovation management and the other related to risk management. In the end, the final version only focused on risk management, with innovation management being left aside, under the responsibility of a Technical Committee created to develop the respective regulations and guidelines [3]. This situation happened due to the existence of a discussion and awareness by the ISO members responsible for the standard that, if clauses related to the theme of innovation were added, together with the other clauses related to quality in ISO 9001:2015, they would have to be seen as certification requirements. This requirement would jeopardise the certification of a vast majority of companies that would not present themselves adequately prepared and able to adapt and formalise the quality standard in its entirety, namely in what concerns innovation.

The ISO 9001:2015 standard pointed out that those organisations were free to apply independently developed methodologies to calculate and assess the impact that certain risks have for them (considering the costs of each risk and the time it will take to eliminate/reduce the consequences of the same) [11]. However, [26] argues that two aspects should be seen as crucial to effectively identify and assess any risk, namely the creation of comprehensive risk classification and the creation of a risk management system for innovation, as they allow organisations to ascertain not only the nature of the risk in question but also the reason for its cause.

Ref. [3] also refers to the importance of organisations presenting ambidexterity, that is, being able to innovate simultaneously both at an incremental and radical level, in search of the realisation of continuous improvements and the achievement of operational excellence. Corroborating what had been defended, [3] concludes that there is a relationship between quality management and innovation management, where the level of support that both have in each other is increasingly evident, being the focus and knowledge that both hold and require from customers an inescapable aspect between them.

\subsection{Innovation Norms}

In recent decades, the topic of "innovation" has incited several discussions in the scientific community as it is increasingly considered an essential element for the survival of organisations in increasingly demanding and competitive markets [27]. As a result, several innovation models have been developed over the years to try to formalise and standardise thoughts and approaches related to innovation [28,29].

The author of [30] argues that the transition from the expanding markets and economic growth of the 1950s to the current and highly competitive global market was reflected in the parallel evolution of management and innovation practices. Moreover, this evolution was accompanied by certain types of innovation models conceived over different generations that sought to be representative of the progress and development of the innovative approaches of the respective era [31].

In a more current perspective, [32] still considers a sixth generation that requires an interaction between innovation systems and networks. In this generation, the central element is the "innovative milieu" defined by the author as "a creative combination of 
generic knowledge and specific skills, in addition to a territorial organisation and an essential component of the technical and economic creative process". According to [33], sixth-generation models do not focus on internal ideas or closed networks but rather seek an opening to the market, enabling an external generation of ideas that may come from customers or other companies in the area.

However, and even before the sixth generation, there was an attempt to create a model with a more contemporary, adaptable and interactive perspective where R\&D was not placed as a permanent or usual starting point for the innovation process. Ref. [34] created a model called the "chain-linked model", whose main highlight was the fact that innovation can start at different stages or originate from various innovative sources. Basically, for the authors of this model, innovation could originate in different ways, either through continuous interactions, such as sporadic or conditional interactions, or as the result of top-down or bottom-up processes, thus eliminating the presupposed associated staticity to the innovation process [35].

Based or not on this model, what was found was that several countries ended up choosing to create an innovation regulation that would help companies in the way they managed their systems, processes, activities or innovation initiatives. As a result, from the European perspective, country-wide and European standards on innovation were developed throughout the last fifteen years, namely UNE 166002:2006 [36] (Spain) (later revised by UNE 166002:2014 [37] and UNE 166002:2021 [38]), NP 4457:2007 [39] (Portugal) (under revision as NP 4457:2021 [40]), BS 7000-1:2008 [41] (United Kingdom) and FD X50-271:2013 [42] (France).

The creation of these standards led to the need to have them unified as an international standard, as described previously, and from that process, the ISO 56000 series was born.

None of the international standards of innovation developed or under development intends to limit the creative process of idealising companies' innovation projects. Instead, they seek to reference some of the best practices that lead to the emergence of a more collaborative environment and language between the different stakeholders in the innovation process. The emphasis is more on collective action and collaborative learning to foster innovation. With the adoption of these standards, a company may find it easier to reduce or even eliminate some of its waste, thus adding more value to its business model [2].

In summary, what was intended with the creation of the ISO 56000 series of standards was to define standards that would transmit a set of references and procedures that would enable the existence of a more collaborative environment that went beyond the national borders of each country. In this way, some of the cultural barriers in certain countries with the power to embrace synergies capable of interceding and transforming industrial sectors would be reduced or attenuated, giving rise to increasingly sustainable industries.

This regulation, in addition to guiding organisations towards creating an innovation policy for the development of new processes/products/services following their organisational objectives, also seeks to make them include and install in the mentality of their employees a set of innovation principles with the power to shape the way they see it, giving them a broader perspective as to its benefits and barriers, thus reducing their resistance to changes and possible imprisonment of ideas.

As it can be implemented in any organisation regardless of its size, area or maturity, this guidance essentially conveys lessons that focus on different areas of action, seeking to facilitate the definition and establishment of objectives and performance indicators to assess the results of its innovation system [3].

As previously mentioned, ISO 56002:2019 is based on the principles of innovation management [5]. It is schematically represented how the structure of the innovation management system should be viewed, relating it to the different clauses of the standard and the PDCA approach.

This standard also refers to the need for an appropriate structure to manage the risks and uncertainties associated with the organisation's market, especially in the earliest stages of its creative processes. The structure that is adopted also allows for an alignment with 
some international standards, such as ISO 9001:2015 and ISO 14001:2015 [43], enabling a more effective integration, development, implementation, maintenance and continuous improvement of the innovation management system.

The adoption of this standard, together with the innovation tools, facilitates and boosts the innovation process of any company by providing principles that allow it to structure and organise its internal innovation processes, maximise innovation efforts and harness the knowledge and creativity of its employees and those with whom it collaborates externally and make possible an integration with other existing management systems [2].

\subsection{Integrated Management Systems}

Over the years, there has been an increased interest of organisations in adopting the ISO standards. For this reason, ISO began to pay attention to the need to make possible the adoption and integration of the different systems present in its standards by defining a base structure that would be common among all of them and which is useful for organisations that meet the requirements of two or more management system standards. This interest shown by organisations may be justified based on customers' constant search for better products/services, increased competition between organisations, government regulations and increased concern to reduce costs associated with the business models of each one [9].

However, it is not enough to have the will and interest in implementing them. It also means to be able to implement each management system according to ISO standards. Furthermore, this integration into a single system needs to have an aligned structure and management systems so that it can coordinate its organisational activities and, consequently, increase the motivation of its employees and improve organisational sustainability [44].

An integrated management system can be understood as a "construction to avoid duplication of tasks that seeks to take advantage of the common elements of two or more separate systems, putting them to work together in a single and more efficient integrated management system" [45]. By integrating different management systems into one, organisations can continuously improve their internal processes by starting to perform more effectively and efficiently the management of risks related to the delivery of products and services for both their customers and for any of its stakeholders [46].

According to [45], it is also necessary to pay attention to the fact that the level of systems integration varies depending on the organisation. For example, the degree of integration of a management system initially independent within the company may be conditioned by factors such as its integration strategy, methodology, maturity or internal motivations. In addition, the authors also mention the existence of other types of aspects that may also influence the achievement of the expected success with it, such as the type of industry to which the companies belong and the size that each one has, also relating to effectiveness and sustainability of systems integration with each organisation's resource allocation capacity.

In case an organisation intends to integrate different management systems, [47] proposes the following process:

1. Map key business processes;

2. Analyse business processes using flowcharts;

3. Identify risks-business, environmental, health and safety at work or quality;

4. Cross-reference the clauses of Annex SL or the ISO standards individually;

5. Formulate operational policies that will govern the processes;

6. Develop procedures or other methodologies to control each business process that will define who does what, where and how;

7. Implement controls and communicate to all interested parties;

8. Evaluate the effectiveness of the processes;

9. Review and improve.

According to the authors, any organisation can achieve such integration as to enable the improvement of its global performance, increase the involvement of all individuals at 
an internal level, reduce document duplication and avoid unnecessary risks by carrying out better risk management more effectively and more efficiently.

However, literature $[46,48-50]$ reports that the creation of integrated management systems, especially in what concerns quality and environment, is not always straightforward, with difficulties in the lack of certification support [51] and difficulties with the management of the organisational culture [52] leading to the need for organisations to make a serious assessment of the costs and benefits associated with the implementation of integrated management systems.

\subsection{Integration Barriers between ISO 56002:2019 and ISO 9001:2015}

As mentioned previously, ISO 56002:2019 has significant structural similarities with the current ISO 9001:2015 (see also Appendix A), which could serve as a determining, driving and facilitating factor capable of attracting companies that already have ISO 9001:2015 implemented to integrate it, as they would only have to make some changes concerning what they would have previously adopted, namely in clauses 4.4, 6.3, 8.2, 8.3 and 10.2.

Despite the differences noted, most clauses are compatible and can be integrated into a single management system. Furthermore, a good part of each standard can be integrated in a way that makes it possible to make any organisation more consistent and less complex.

The integration of management systems, in general, increases the satisfaction of internal and external customers, improves communication between all levels of management and reduces costs associated with the number of necessary audits. In addition, it was concluded that it also allows unification of objectives, processes and resources; reduces bureaucracy by eliminating duplication of policies, processes and records; avoids duplication; improves the organisations' overall effectiveness and efficiency and its competitiveness [53].

However, it can be observed that there is a divergent thematic focus in specific points of both documents, specifically in some clauses of requirements 4, 6, 7, 8 and 10 .

It is also worth mentioning that there is a difference in clauses ( 35 clauses in ISO 9001:2015 and 33 clauses in ISO 56002:2019).

Although small, this differentiation may come to be synonymous with the need to assign new responsibilities and roles to avoid conflicts between organisational structures; to start maintaining additional documentation for each standard; and to carry out audits with a higher level of complexity, contrary to what would be expected [47]. A study by [14], focused on the challenges of integrating quality management and innovation management systems in two different Swedish public organisations, concluded that "the current quality management practice is related to development and maintenance of standardisation and leads to a decreased leeway for innovation". However, it was also possible to perceive, at the same time, that there is "a common expectation and belief [ ... ] that innovation and quality management can be handled in parallel and reinforce each other, but it requires active and conscious efforts within the organisations to develop leeway for innovation".

\section{Materials and Methods}

Based on the previous analysis, the following work consisted of inquiring ISO 9001:2015certified companies about the potential difficulties and benefits in integrating the existing quality management system with an innovation management system, according to the guidelines of ISO 56002:2019.

For that purpose, meetings were held with senior managers and quality managers of three Portuguese SMEs (with NACE code 23 (manufacturer of other nonmetallic mineral products), 28 (manufacturer of general-purpose machinery) and 30 (manufacturer of other transport equipment)) to discuss the existing gaps in the integration of both management systems.

The discussion started with the analysis of the Quality Management Systems of the involved companies and a verification of the existing quality and innovation processes and procedures. From there, complementary questions were asked about specific requirements 
to obtain a clearer perception of the existing actions aimed at specific requirements of ISO 9001:2015, and the clauses that might be most problematic when addressing the implementation of an Integrated Management System including Quality and Innovation were identified.

Using a framework for discussion based on [54], an assessment of difficulties of implementing the integrated management system was made, and the potential benefits that can be achieved from both the internal perspective and from the external perspective were identified and discussed.

The internal benefits and difficulties were analysed from the strategic, tactical and operational perspective, whereas the external benefits and difficulties were analysed from the institutional and stakeholder perspective.

\section{Results and Discussion}

In what concerns the implementation of an integrated management system, and considering the existent quality management systems of the organisations addressed, the main difficulties foreseen with the implementation of the innovation management system and the underlying integrated management system were the following:

Regarding clause " 4 . Context of the organisation", the subclause " 4.4 Establishing the innovation management system" of the ISO 56002:2019 [5], the standard must be articulated with subclause " 4.4 Quality management system and its processes" of the ISO 9001:2019 standard.

The integrated management system may lead to the need to reassess internal communication approaches, paying attention to and promoting a favourable culture for the execution of innovation activities. It was mentioned that such promotion should include the existence of an incentive and support for innovation activities such that they are able to not only encourage the dissemination of feedback, suggestions, experiments and learning from past mistakes by all hierarchical levels but also encourage and recognize successful innovative behaviours (e.g., creation of motivation policies) and a more proactive approach to people development and training.

Considering collaborations with external entities, even though all the interviewed entities have collaboration with key suppliers, universities and R\&D centres, it was necessary to align that collaboration with the overarching innovation vision, monitoring the strategic relevance of these collaborations, both from the internal and the external perspective, especially regarding enhancing knowledge sharing among the parties, as well as a clearer identification of existing skills and resources not only within the organisations but also among the collaborating entities.

In what regards clause "6. Planning", the subclause "6.3 Planning of changes" in ISO 9001:2015 differs substantially from the subclause "6.3 Organisational structures" in ISO 56002:2019. Traditionally, the interviewed organisations rely on traditional project-based product development departments, either in using a push strategy or a pull strategy to address the marketplace. This new approach will reinforce the latter, leading to the need to introduce new creativity mechanisms and the reinforcement of existing cooperation with customers and suppliers in the development of projects and programs. This change must also take into consideration subclause "6.4 Innovation portfolios" in ISO 56002:2019 that will demand the introduction of the concept of portfolio in the organisations, demanding a new analysis dimension that departs from the traditional project/program management approach, and require their alignment with the overarching strategy of the organisation and the underlying procedures.

In clause "7. Support", the introduction of three new subclauses "7.6 Tools and methods", "7.7 Strategic intelligence management" and "7.8 Intellectual property management" will require careful planning in the selection of the tools and methods of innovation that exist in the marketplace, most of them developed by large companies and addressed to start-up-like organisations. Examples include the tools developed by IDEO (2021) for 
brainstorming or the Design Sprint by Google Ventures (2019) and those that usually do not have a formal training mechanism for their implementation in the organisations.

The strategic intelligence management subclause can be supported by "ISO 56006Innovation management-Tools and methods for strategic intelligence managementGuidance" [55] that is currently in stage 60.00 (International Standard under publication). The analysed companies usually demonstrated they had intelligence mechanisms with information provided by stakeholders. However, the ensuing results from this process were not properly systematized nor divulged within the companies.

The intellectual property management subclause can be supported by the "ISO 56005:2020-Innovation management-Tools and methods for intellectual property management-Guidance" [8]. Even though the inquired companies demonstrate that they properly protect the knowledge created, the valorisation mechanisms of the protected knowledge are usually absent, with little evidence of the enforcement due to lack of specialized resources that are required for a proper and effective implementation of these procedures.

In clause "8. Operations", the main differences lie in subclause "8.2 Innovation initiatives" and subclause "8.3 Innovation processes" of the ISO 56002:2019 standard.

The former is related to the way the organisation manages the initiatives that, although it has similitudes with the clause " 8.2 Requirements for products and services" of the ISO 9001:2015 standard in what concerns gathering the internal and external requirements, it does not address other innovation specific issues such as the way how each initiative must be approached.

The latter is related to the way the organisation manages the innovation process, following procedures that enhance flexibility and adaptability of the process. The existing procedures for the design and development of products are aligned with the innovation processes; however, they need to be revised to be aligned with the other mechanisms, especially regarding the subclause "4.4. Establishing the innovation management system".

To assess the degree of interest and relevance that ISO 56002:2019 presents from the perspective of enquired organisations and based on the analysis made when filling out the questionnaire to assess the organisation's perception of how it views a possible integration between its QMS and a future IMS, the following results stand out:

In what concerns strategic internal benefits, the inquired organisations reported that it would enable the creation of value and an increase in the organisations' competitive advantage, enabling the creation of integrated procedures regarding quality and innovation that would enhance continual improvement mechanisms. It would also allow greater transparency and efficiency in the organisations' functioning, lowering the complexity of the internal management and reducing risks by adopting more straightforward and more focused management systems. However, it would present challenges and difficulties in the overarching strategic management and in the creation and organisation of an integrated management system.

On the functional end of the internal benefits, the main benefits foreseen are concerned with avoiding the duplication of efforts and with the optimized use of resources, since standard continual improvement and systematic innovation actions and methods will be applied, enabling more efficient innovation projects that can be articulated with internal reengineering and cost-reduction actions. Regarding the technological development and the technology transfer mechanisms, it is foreseen that coherent procedures will optimize the value captured from the innovation project results.

However, it is foreseen that an ineffective implementation of the integrated management system may lead to problems that will arise in the mid-long term. This problem is especially relevant since the combination and integration of the different systems is not always clear and usually it lacks a structure upon which the integrated system is built, with problems integrating objectives, processes and resources in the same management system in a coherent way. Moreover, the lack of specialized resources may hamper the 
operationalization of the integrated management systems, especially due to its scarcity in SMEs.

One final note is related to the cost of performing several audits. Although ISO 56002:2019 is a guidelines standard, in the near term, it is expected to become a requirements standard once the ISO/AWI 56001-Innovation management-Innovation management system-Requirements (currently under development) become approved, leading to the need to have multiple third-party audits to certify the integrated management system.

From the operational perspective, the possibility of reduction in the number of procedures and records is the main internal benefit, that, however, clashes with the difficulties foreseen in the implementation of the integrated reports.

In what concerns human resources, the implementation of the integrated management system may lead to improved communication and sharing of information between different organisational levels, with a clear definition of responsibilities, especially in what concerns the implementation of innovation projects, and an improved and clearer roadmap in what concerns training activities to be more aligned with the future vision of the organisations. On the other hand, it is feared that, if not properly articulated and implemented, the management system may lead to conflicts due to the overlap of interests and motivations.

Regarding external benefits, it is stated that the implementation of the integrated management system will allow a more effective response to the changes in the marketplace, especially since the marketplace strategic intelligence mechanisms, already existent for the QMS, will highlight the innovation roadmap of the industry, providing management with a clearer perspective of the future trends.

The involvement of the stakeholders will be of benefit, transmitting a positive image of the company to the marketplace and providing its customers and suppliers with a platform for the development of innovative solutions that can be integrated and coherent, aligning the supply chain and the introduction of customized solutions to the customers.

\section{Conclusions}

The results obtained point to the existence of a significant set of practices in the field of quality that can support and facilitate the formalization of integrated management systems including quality and innovation management systems. Nevertheless, it appears that, to ensure a correct and adequate transition to an IMS, companies must follow the guidelines presented throughout ISO 56002:2019 that reveal objective examples of implementation of certain practices, as it categorically explains the key points that should be included in the innovation processes and/or initiatives to ensure the total success of its innovation activities.

Moreover, the analysis of the potential benefits and difficulties resulting from the integrated management systems reveals that most of the problems reside in the lack of qualified resources to support the integration process and the underlying administrative burden on the organisation.

Considering all the information gathered, there is, in fact, an interest and capacity on the part of the companies to proceed with the integration of the QMS with a future implementation of an integrated management system including quality and innovation.

Even though they lack adequate human resources to implement and maintain these systems, the involved companies revealed that they have the appropriate infrastructure and resources to be able to develop innovative systems and mechanisms that increase their value in the market.

However, they must address chronic problems of industrial SMEs in Portugal, such as the promotion of greater involvement of employees in defining objectives and innovation strategies to improve its culture of innovation. The implementation of systematic measurement of the innovation activities must also be pursued so that a company can, over time, compare its activities, technologies, competences, etc. with that of other entities operating in the market to increase its competitive advantage vis-à-vis their main competitors. 
As an overall conclusion of the study undertaken, it seems that the perception of the managers of the companies interviewed is that the type of relation between quality management and innovation management systems is synergetic and not conflicting by using the typology of [15]. This means that the combination of quality management and innovation management in an integrated management system contributes to fostering the innovation process within a company, enabling an environment for innovation development [15]. The results seem, also, to contradict the claim of [56] that quality professionals are not very much aware of the innovation phenomena and vice-versa. At least for the case of the three companies studied, although some problems are recognized with the integration of the two management systems, it seems that the companies' managers are aware of the importance of their integration.

Although interesting results have been obtained in this paper regarding the process of integration of an innovation management system in an already existent quality management system of a company, the generalization of the results should be avoided, and more research is needed. Firstly, the integration of management systems is often conditioned by issues related to costs, time and benefits [13]. Secondly, the process of innovation depends on several contextual factors, such as industry, company size, innovation ecosystem, the life cycle of the innovation and role of stakeholders [15]. Finally, whether a company can simultaneously reach a high level of efficiency (brought about by implementing a quality management system) and a high level of innovation (made possible by the implementation of an innovation management system) has been questioned by several authors [14]. If this is not possible, it could jeopardize the implementation of an integrated management system.

Author Contributions: Conceptualization, A.L. and D.P.; methodology, A.L. and D.P.; validation, A.L., D.P. and A.G.; investigation, A.L. and D.P.; resources, A.L. and D.P.; data curation, A.L. and D.P.; writing-original draft preparation, A.L., D.P., A.G. and J.C.; writing-review and editing, A.L., D.P., A.G. and J.C.; supervision, D.P. and J.C. All authors have read and agreed to the published version of the manuscript.

Funding: This research received no external funding.

Institutional Review Board Statement: Not applicable.

Conflicts of Interest: The authors declare no conflict of interest.

\section{Appendix A}

Table A1. Iso 9001:2015 vs. ISO 56002:2019 (based on [5,11]).

\begin{tabular}{|c|c|}
\hline ISO 9001:2015-Quality Management Systems-Requirements & $\begin{array}{c}\text { ISO 56002:2019-Innovation Management-Innovation } \\
\text { Management System-Guidance }\end{array}$ \\
\hline $\begin{array}{l}1 \\
\text { 2. Norma } \\
\text { 3. Terms } \\
\text { 4. Context o }\end{array}$ & $\begin{array}{l}\text { eferences } \\
\text { efinitions } \\
\text { Organisation }\end{array}$ \\
\hline 4.1 Understanding the organisation and its context & 4.1 Understanding the organisation and its context \\
\hline 4.2 Understanding the needs and expectations of interested parties & 4.2 Understanding the needs and expectations of interested parties \\
\hline 4.3 Determining the scope of the quality management system & 4.3 Determining the scope of the innovation management system \\
\hline 4.4 Quality management system and its processes & 4.4 Establishing the innovation management system \\
\hline \multicolumn{2}{|c|}{ 5. Leadership } \\
\hline $\begin{array}{l}\text { 5.1 Leadership and commitment } \\
\text { 5.2 Policy }\end{array}$ & $\begin{array}{l}\text { 5.1 Leadership and commitment } \\
5.2 \text { Innovation policy }\end{array}$ \\
\hline 5.3 Organisational roles, responsibilities and authorities & 5.3 Organisational roles, responsibilities and authorities \\
\hline \multicolumn{2}{|l|}{ 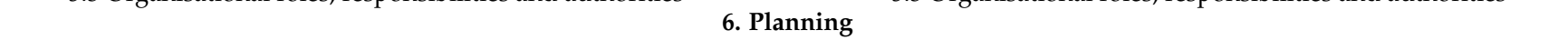 } \\
\hline 6.1 Actions to address risks and opportunities & 6.1 Actions to address opportunities and risks \\
\hline 6.2 Quality objectives and planning to achieve them & 6.2 Innovation objectives and planning to achieve them \\
\hline \multirow[t]{2}{*}{ 6.3 Planning of changes } & 6.3 Organisational structures \\
\hline & 6.4 Innovation portfolios \\
\hline
\end{tabular}


Table A1. Cont.

\begin{tabular}{|c|c|}
\hline ISO 9001:2015-Quality Management Systems-Requirem & $\begin{array}{c}\text { ISO 56002:2019-Innovation Management-Innovation } \\
\text { Management System-Guidance }\end{array}$ \\
\hline \multicolumn{2}{|c|}{ 7. Support } \\
\hline 7.1 Resources & 7.1 Resources \\
\hline 7.2 Competence & 7.2 Competence \\
\hline 7.3 Awareness & 7.3 Awareness \\
\hline 7.4 Communication & 7.4 Communication \\
\hline 7.5 Documented information & 7.5 Documented information \\
\hline & 7.6 Tools and methods \\
\hline & 7.7 Strategic intelligence management \\
\hline & 7.8 Intellectual property management \\
\hline \multicolumn{2}{|r|}{ 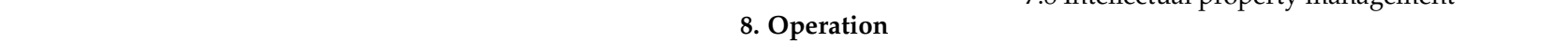 } \\
\hline 8.1 Operational planning and control & 8.1 Operational planning and control \\
\hline 8.2 Requirements for products and services & 8.2 Innovation initiatives \\
\hline 8.3 Design and development of products and services & 8.3 Innovation processes \\
\hline \multicolumn{2}{|l|}{ 8.4 Control of externally provided processes, products and services } \\
\hline \multicolumn{2}{|l|}{ 8.5 Production and service provision } \\
\hline \multicolumn{2}{|l|}{ 8.6 Release of products and services } \\
\hline \multicolumn{2}{|l|}{ 8.7 Control of nonconforming outputs } \\
\hline \multicolumn{2}{|c|}{ 9. Performance Evaluation } \\
\hline 9.1 Monitoring, measurement, analysis and evaluation & 9.1 Monitoring, measurement, analysis and evaluation \\
\hline 9.2 Internal audit & 9.2 Internal audit \\
\hline 9.3 Management review & 9.3 Management review \\
\hline \multicolumn{2}{|c|}{ 10. Improvement } \\
\hline 10.1 General & 10.1 General \\
\hline 10.2 Nonconformity and corrective action & 10.2 Deviation, nonconformity and corrective action \\
\hline 10.3 Continual improvement & 10.3 Continual improvement \\
\hline
\end{tabular}

\section{References}

1. Fonseca, M.L. From quality gurus and TQM to ISO 9001:2015: A review of several quality paths. Int. J. Qual. Res. 2015, 9, 167-180.

2. Idris, M.C.; Durmuşoğlu, A. Innovation management systems and standards: A systematic literature review and guidance for future research. Sustainability 2021, 13, 8151. [CrossRef]

3. Lilja, J.; Hansen, D.; Fredrikson, J.; Richardsson, D. Is innovation the future of quality management?: Searching for signs of quality and innovation management merging. Int. J. Qual. Serv. Sci. 2017, 9, 232-240. [CrossRef]

4. International Organization for Standardization. Innovation Management-Fundamentals and Vocabulary (ISO 56000:2020). 2020. Available online: https:/ / www.iso.org/standard/69315.html (accessed on 2 November 2021).

5. International Organization for Standardization. Innovation Management-Innovation Management System-Guidance (ISO 56002:2019). 2019. Available online: https://www.iso.org/standard/68221.html (accessed on 28 May 2020).

6. International Organization for Standardization. Innovation management-Tools and Methods for Innovation PartnershipGuidance (ISO 56003:2019). 2019. Available online: https://www.iso.org/standard/68929.html (accessed on 2 November 2021).

7. International Organization for Standardization. Innovation Management Assessment—Guidance (ISO/TR 56004:2019). 2019. Available online: https:/ / www.iso.org/standard/69921.html (accessed on 10 November 2021).

8. International Organization for Standardization. Innovation management-Tools and Methods for Intellectual Property Management-Guidance (ISO 56005:2020). 2020. Available online: https://www.iso.org/standard/72761.html (accessed on 10 November 2021).

9. International Organization for Standardization. ISO/IEC Directives, Part 1, Procedures for the Technical Work, SL Annex. 2021. Available online: https://www.iso.org/sites/directives/current/consolidated/index.xhtml\#_idTextAnchor569 (accessed on 10 November 2021).

10. International Organization for Standardization. What's the Difference between a 'Type A' and 'Type B' MSS? 2021. Available online: https:/ / www.iso.org/management-system-standards-list.html (accessed on 5 November 2021).

11. International Organization for Standardization. Quality Management Systems-Requirements (ISO 9001:2015). 2015. Available online: https:/ / www.iso.org/standard/62085.html (accessed on 2 November 2021).

12. International Organization for Standardization. Innovation Management-Innovation Management System-Requirements (ISO/AWI 56001). 2021. Available online: https:/ / www.iso.org/standard/79278.html (accessed on 2 November 2021).

13. Maier, D.; Vadastreanu, A.M.; Keppler, T.; Eidenmuller, T.; Maier, A. Innovation as a Part of an Existing Integrated Management System. Procedia Econ. Financ. 2015, 26, 1060-1067. [CrossRef]

14. Palm, K.; Lilja, J.; Wiklund, H. The challenge of integrating innovation and quality management practice. Total Qual. Manag. Bus. Excell. 2016, 27, 34-47. [CrossRef]

15. Tidd, J. A review and critical assessment of the ISO56002 innovation management systems standard: Evidence and limitations. Int. J. Innov. Manag. 2021, 25, 1. [CrossRef] 
16. Hyland, J.; Karlsson, M. Towards a Management System Standard for Innovation. J. Innov. Manag. 2021, 9, 11-19. [CrossRef]

17. $\mathrm{Ng}$, P.T. Relating quality and innovation: An exploration. Int. J. Qual. Innov. 2009, 1, 3. [CrossRef]

18. Yams, N.B.; Richardson, V.; Shubina, G.E.; Gillblad, D.; Zuboff, S. Integrated AI and Innovation Management: The Beginning of a Beautiful Friendship. Technol. Innov. Manag. Rev. 2020, 10, 11. [CrossRef]

19. International Organization for Standardization. Quality Systems-Model for Quality Assurance in Design/Development, Production, Installation and Servicing (ISO 9001:1987). 1987. Available online: https://www.iso.org/standard/16533.html (accessed on 2 November 2021).

20. International Organization for Standardization. Quality Systems-Model for Quality Assurance in Design, Development, Production, Installation and Servicing (ISO 9001:1994). 1994. Available online: https://www.iso.org/standard/16534.html (accessed on 2 November 2021).

21. International Organization for Standardization. Quality Management Systems-Requirements (ISO 9001:2000). 2000. Available online: https:/ / www.iso.org/standard/21823.html (accessed on 2 November 2021).

22. Sari, Y.; Wibisono, E.; Wahyudi, R.D.; Lio, Y. From ISO 9001:2008 to ISO 9001:2015: Significant changes and their impacts to aspiring organizations. IOP Conf. Ser. Mater. Sci. Eng. 2017, 273, 1. [CrossRef]

23. International Organization for Standardization. Quality Management Systems_Fundamentals and Vocabulary (ISO 9000:2015) 2015. Available online: https:/ / www.iso.org/standard/45481.html (accessed on 2 November 2021).

24. International Organization for Standardization. Quality Management-Quality of an Organization-Guidance to Achieve Sustained Success (ISO 9004:2018). 2018. Available online: https://www.iso.org/standard/70397.html (accessed on 2 November 2021).

25. International Organization for Standardization. Guidelines for Auditing Management Systems (ISO 19011:2018). 2018. Available online: https:/ / www.iso.org/standard/70017.html (accessed on 2 November 2021).

26. Nechaev, A.S.; Ognev, D.V.; Antipina, O.V. Innovation risks: Challenges and prospects. In Proceedings of the International Conference on Trends of Technologies and Innovations in Economic and Social Studies, Tomsk, Russia, 28-30 June 2017; pp. 7-12. [CrossRef]

27. Oliva, F.L.; Semensato, B.I.; Prioste, D.B.; Winandy, E.J.L.; Bution, J.L.; Couto, M.H.G.; Bottacin, M.A.; Mac Lennan, M.L.F.; Teberga, P.M.F.; Santos, R.F.; et al. Innovation in the main Brazilian business sectors: Characteristics, types and comparison of innovation. J. Knowl. Manag. 2019, 23, 135-175. [CrossRef]

28. Tidd, J.; Bessant, J.; Pavitt, K. Managing Innovation: Integrating Technological, Organizational and Market Change, 3rd ed.; John Wiley \& Sons, Ltd.: West Sussex, UK, 1997.

29. Tidd, J.; Bessant, J. Managing Innovation: Integrating Technological, Market and Organizational Change, 4th ed.; John Wiley \& Sons, Ltd.: West Sussex, UK, 2009.

30. Nobelius, D. Towards the sixth generation of R\&D management. Int. J. Proj. Manag. 2004, 22, 369-375. [CrossRef]

31. O'Raghallaigh, P.; Sammon, D.; Murphy, C. The design of effective theory. Syst. Signs Actions 2011, 5, 117-132.

32. Barbieri, J.C.; Álvares, A.C.T. Sixth generation innovation model: Description of a success model. RAI Rev. Adm. Inovação 2016, 13, 116-127. [CrossRef]

33. Taferner, B. A Next Generation of Innovation Models? An Integration of the Innovation Process Model Big Picture Towards the Different Generations of Models. Rev. Innov. Compet. 2017, 3, 47-60. [CrossRef]

34. Kline, S.; Rosenberg, G. An Overview of Innovation. In The Positive Sum Strategy: Harnessing Technology for Economic Growth; National Academy Press: Washington, DC, USA, 1986; pp. 275-305.

35. Micaëlli, J.-P.; Forest, J.; Coatanéa, É.; Medyna, G. How to improve Kline and Rosenberg's chain-linked model of innovation: Building blocks and diagram-based languages. J. Innov. Econ. 2014, 15, 59. [CrossRef]

36. Asociación Española de Normalización. R\&D\&i Management: R\&D\&i Management System Requirements (UNE 166002:2006). 2006. Available online: https://www.une.org/encuentra-tu-norma/busca-tu-norma/norma?c=N0036136 (accessed on 2 November 2021).

37. Asociación Española de Normalización. R\&D\&i Management: R\&D\&i Management System Requirements (UNE 166002:2014). 2014. Available online: https://www.une.org/encuentra-tu-norma/busca-tu-norma/norma?c=N0052892. (accessed on 2 November 2021).

38. Asociación Española de Normalización. R\&D\&i Management: R\&D\&i Management System Requirements (UNE 166002:2021). 2021. Available online: https://www.une.org/encuentra-tu-norma/busca-tu-norma/norma?c=N0065421 (accessed on 2 November 2021).

39. Instituto Português da Qualidade. Gestão da Investigação, Desenvolvimento e Inovação (IDI); Requisitos do Sistema de Gestão da IDI (NP 4457:2007). 2007. Available online: https:/ /lojanormas.ipq.pt/product/np-4457-2007/ (accessed on 2 November 2021).

40. Instituto Português da Qualidade. Gestão da Investigação, Desenvolvimento e Inovação (IDI). Requisitos so Sistema de Gestão da IDI (NP 4457:2021). 2021. Available online: http://www1.ipq.pt/PT/Normalizacao/Inquerito_Publico_Projeto_Norma/Pages/ Projectos_Norma_em_Inquerito.aspx (accessed on 2 November 2021).

41. British Standards Institution. Design Management Systems-Guide to Managing Innovation (BS 7000-1:2008). 2008. Available online: https://shop.bsigroup.com/products/design-management-systems-guide-to-managing-innovation\%0A (accessed on 2 November 2021). 
42. Association Française de Normalisation. Management de l'innovation-Guide de Mise en Euvre D'une Démarche de Management de L'innovation (FD X50-271:2013). 2013. Available online: https://www.boutique.afnor.org/fr-fr/norme/fd-x502 71/management-de-linnovation-guide-de-mise-en-oeuvre-dune-demarche-de-manageme/fa176217/1420\%0A (accessed on 2 November 2021).

43. International Organization for Standardization. Environmental Management Systems-Requirements with Guidance for Use (ISO 14001:2015). 2015. Available online: https://www.iso.org/standard/60857.html (accessed on 2 November 2021).

44. Bernardo, M.; Gotzamani, K.; Vouzas, F.; Casadesus, M. A qualitative study on integrated management systems in a non-leading country in certifications. Total Qual. Manag. Bus. Excell. 2018, 29, 453-480. [CrossRef]

45. Gianni, M.; Gotzamani, K.; Tsiotras, G.D. Multiple Perspectives on Integrated Management Systems and Corporate Sustainability Performance. J. Clean. Prod. 2017, 168, 1297-1311. [CrossRef]

46. Nunhes, T.; Motta, L.; Oliveira, O. Evolution of integrated management systems research on the Journal of Cleaner Production: Identification of contributions and gaps in the literature. J. Clean. Prod. 2016, 139, 1234-1244. [CrossRef]

47. Savage, C.; Nicholas, S. ISO 9001, 14001 and 45001: Managing Risk Effectively and Efficiently in the Construction Industry. 2017. Available online: https:/ / saiassurance.com/iso-9001-14001-and-45001-managing-risk-effectively-and-efficiently-in-theconstruction-industry / (accessed on 7 October 2021).

48. Blasco-Torregrosa, M.; Perez-Bernabeu, E.; Palacios-Guillem, M.; Gisbert-Soler, V. How do firms integrate management systems? A comparative study. Total Qual. Manag. Bus. Excell. 2021, 32, 777-793. [CrossRef]

49. De Oliveira, O.J. Guidelines for the integration of certifiable management systems in industrial companies. J. Clean. Prod. 2013, 57, 124-133. [CrossRef]

50. Bernardo, M.; Casadesus, M.; Karapetrovic, S.; Heras, I. Integration of standardized management systems: Does the implementation order matter? Int. J. Oper. Prod. Manag. 2012, 32, 291-307. [CrossRef]

51. Zeng, S.X.; Shi, J.J.; Lou, G.X. A synergetic model for implementing an integrated management system: An empirical study in China. J. Clean. Prod. 2007, 15, 1760-1767. [CrossRef]

52. Wilkinson, G.; Dale, B.G. Integrated management systems: An examination of the concept and theory. TQM Mag. 1999, 11, 95-104 [CrossRef]

53. Khan, P.A. Does adoption of ISO 56002-2019 and green innovation reporting enhance the firm sustainable development goal performance? An emerging paradigm. Bus. Strateg. Environ. 2021, 30, 2922-2936. [CrossRef]

54. Simon, A.; Karapetrovic, S.; Casadess, M. Difficulties and benefits of integrated management systems. Ind. Manag. Data Syst. 2012, 112, 828-846. [CrossRef]

55. International Organization for Standardization. Innovation Management-Tools and Methods for Strategic Intelligence Management-Guidance (ISO/DIS 56006). 2020. Available online: https://www.iso.org/standard/72621.html (accessed on 20 July 2020).

56. Anttila, J.; Jussila, K. Striving for benefits of sustainability from the interactivity of quality and innovation. J. Clean. Prod. 2019, 212, 409-419. [CrossRef] 